\title{
Simple and Rapid Proteomic Analysis by Protease-Immobilized Microreactors
}

\author{
Hiroshi Yamaguchi ${ }^{1,2}$, Masaya Miyazaki ${ }^{1,3}$ and Hideaki Maeda ${ }^{1,3}$ \\ ${ }^{1}$ Measurement Solution Research Center, \\ National Institute of Advanced Industrial \\ Science and Technology \\ ${ }^{2}$ Liberal Arts Education Center, \\ Aso campus, Tokai University \\ ${ }^{3}$ Interdisciplinary Graduate School of \\ Engineering Science, Kyusyu University \\ Japan
}

\section{Introduction}

Proteomics is the large-scale study of proteins, particularly their stuructures and functions. One of the most important point is to develop efficient and rapid approachehes to identify the target proteins. Peptide mass mapping and tandem mass spectrometry (MS/MS)-based peptide sequencing are key methods in current protein identification for proteomic studies. Proteins are usually digested into peptides that are subsequently analyzed by MS. Therefore, proteolysis by sequence-specific proteases is the key step for positive sequencing in proteomic analysis integrated with MS (Aebersold \& Mann, 2003). The conventional method of in-solution digestion by proteases is a time-consuming procedure (overnight at $37^{\circ} \mathrm{C}$ ). The substrate/protease ratio must be kept high (generally $>50$ ) in order to prevent excessive sample contamination by the protease and its auto-digested products. But this leads to a relatively slow digestion. In addition, obtaining reliable peptide maps and meaningful sequence data by MS analysis requires not only the separation of the digested peptides but also strictly defined proteolysis conditions (Domon \& Aebersold, 2006; Witze et al., 2007). In addition, the ionization efficiency of the digested fragments including a modified peptide such as a phosphopeptide is dependent on peptide-size or peptidesequence, which directly correlates with sequence coverage of the target protein by MS analysis. Furthermore, peptide recovery from in-solution digestion is highly dependent on the structural properties of the target proteins because proteins with rigid structures, e.g. by disulfide bonds tend to be resistant to complete digestion. In fact, the typical preparation of a sample for proteolysis includes denaturation, reduction of disulfide bonds, and alkylation procedures lead to a decrease the conformational stability. It is obvious that insufficient sequence coverage could compromise the accuracy of proteome characterization. Therefore, it is important to develop novel digestion methods to achieve a highly efficient proteolysis for MS-based peptide mapping (Park \& Russell, 2000; Slysz et al., 2006).

A microreactor is a suitable reaction system for handling small-volume samples in a microchannel to perform chemical or enzymatic reactions. Enzyme-immobilized 
microreactors have been widely utilized in chemical and biotechnological fields (Liu et al., 2008; Ma et al., 2009; Miyazaki et al., 2008; Asanomi et al., 2011). The protease-immobilized microreactor provides several advantages for proteolysis (Ma et al., 2009); e.g. low degree of auto-digestion even at high protease concentrations and a large surface and interface area that leads to rapid proteolysis. Furthermore, the immobilized proteases on the microchannel walls can be easily isolated and removed from the digested fragments prior to MS, which means elimination of the requirement to stop the reaction by chemical or thermal denaturation after digestion. These features can contribute to higher sequence coverage compared to the approach based on in-solution digestion. High sequence coverage is important to enhance the probability of identification of the protein and increase the likelihood of detection of structural variants generated by processes such as posttranslational modifications.

Several methods for protease immobilization have been reported, wherein the protease, usually trypsin, has been immobilized in microchips by sol-gel encapsulation (Sakai-Kato et al., 2003; Wu et al., 2004), covalently bounded (Lee et al., 2008; Fan \& Chen, 2007) and physically adsorbed onto different supports (Liu et al., 2006). In addition, trypsinimmobilized magnetic particles have been developted to carry out proteolysis with a short digestion time ( $\mathrm{Li}$ et al., 2007a; Chen \& Chen, 2007). However, preparations of these protease-immobilized microreactors require multi-step procedures consuming considerable amounts of time and effort. Therefore, a facile preparation method of the enzymeimmobilized microreactor is desirable for the routine proteolysis step in proteomic analysis. In addition, reusability is also an important feature required for laboratory use.

We developed the procedure for immobilizing enzymes on the internal surface of the polytetrafluoroethylene (PTFE) microtube by forming an enzyme polymeric membrane through a cross-linking reaction in a laminar flow between lysine (Lys) residues on the protein surfaces (Honda et al., 2005) or between the mixture of proteins with isoelectric point $\mathrm{p} I<7.0$ and poly-Lys (Honda et al., 2006). A typical sample preparation for proteolysis involves multi-steps (denaturation, reduction and alkylation) that are expected to produce enhancement of digestion efficiency. Because enzyme-immobilized microreactors prepared by our cross-linking method have excellent reaction performance and stability against high temperature and high concentration of denaturant (Honda et al., 2005), the microreactors are expected to achieve efficient digestion during the denaturation process. This idea inspired us to apply protease-immobilized microreactor for rapid and accurate proteolysis in proteomic analysis.

This chapter addresses the use of protease-immobilized microreactors with MS for proteomic applications. Preparation of the microreactors and examples of a simple and rapid analysis of protein sequence and protein post-translational modification are presented.

\section{Preparation of protease-immobilized microreactors}

A typical procedure for cross-linking enzyme involves activation of the primary amine groups of enzyme with cross-linker to create aldehyde groups that can react readily with other primary amine groups of enzymes (Honda et al; 2005; Ma et al., 2009; Miyazaki \& Maeda, 2006). Cross-linking yields depend on the number of the Lys residues of enzyme. Therefore, the acidic or neutral enzyme $(\mathrm{p} I<7.0)$ cannot be cross-linked efficiently merely by the use of cross-linker such as glutaraldehyde (GA). Although high concentration of 
cross-linker can increase the cross-linking yield, it often causes a change of its conformation, engendering a reduction of its catalytic activity (Wang et al., 2009). To overcome this difficulty, poly-Lys was used as the amine donor in this study. It is expected that the large number of primary amine groups of poly-Lys can improve the cross-linking yield with lower concentration of cross-linker than those in reported procedures (typically $5-10 \%$ of GA, v/v) (Ma et al., 2008; Fan \& Chen, 2007).

\subsection{Protease}

We prepared two protease-immobilized microreactors for proteomic analysis; trypsin(TY) and chymotrypsin- (CT) immobilized microreactors. TY hydrolyses peptide bonds after Arg and Lys residues. Because these basic residues are usually located on the surface of protein, especially in soluble proteins, the digested peptides generally fit the range $(<2$ $\mathrm{kDa}$ ) required for analysis by MS. However, if Pro residue is located at the C-terminal side of Arg or Lys, hydrolysis will not occur. Moreover, it is possibility that the conformational stability of the protein e.g. by disulfide bond has a resistance for proteolysis. These possibilities will cause the digested peptides to become too large to be detected by MS. Therefore, aside from TY, other endoproteases can be used for MS-based analysis to cover the whole sequence of the target protein. CT hydrolyses peptide bonds after aromatic residues (Phe, Trp and Tyr) and after Leu and Met in a less specific way and is often used for proteolysis of hydrophobic proteins such as membrane proteins (Fischer \& Poetsch, 2006; Temporini et al., 2009).

\subsection{Preparation techniques for the protease-immobilized microreactors}

A microfluidics-based enzyme-polymerization technique (Honda et al., 2005; Honda et al., 2006) was used for the preparation of protease-immobilized microreactors. The procedure for immobilizing protease on the internal surface of the PTFE microtube by forming an enzyme polymeric membrane through a cross-linking reaction between Lys residues on the protein surface are presented in Fig. 1 . The solutions were introduced to the PTFE microtube from gas tight syringes by syringe pumps. The combination of GA $(0.25 \%, \mathrm{v} / \mathrm{v})$ and paraformaldehyde (PA) $(4 \%, \mathrm{v} / \mathrm{v})$ provided better cross-linking yields between the proteases maintaining their activities (Honda et al., 2005; Honda et al., 2006). Because the $\mathrm{pI}$ value of $\mathrm{CT}$ (8.6) is close to the $\mathrm{pH}$ value of the reaction buffer (8.0), this probably leads to low polymerization yield. Thus, poly-Lys supporting polymerization procedure was used for the preparation of CT-immobilized microreactor. The molecular weight of poly-Lys was $62 \mathrm{kDa}$. Resulting Schiff base was reduced by $\mathrm{NaCNBH}_{3}$. On the other hand, for TYimmobilized microreactor, poly-Lys was omitted because the $\mathrm{p} I$ value of trypsin was 10.5 and poly-Lys was a substrate for trypsin. To avoid autolysis of protease in bulk solution during the cross-linking reaction, the preparation of microreactor was conducted at $4{ }^{\circ} \mathrm{C}$ (Yamaguchi et al., 2009).

Protease immobilization on PTFE tube was analyzed by the Bradford method in order to measure the total polymerized enzyme. For example, $50 \mu \mathrm{g}$ CT was formed by polymerizing on a $1 \mathrm{~cm}$ long PTFE tube. Other enzymes were also immobilized on PTFE tubes with similar concentration. Because these concentrations of the immobilized proteases are higher than those used in the experimental conditions of in-solution digestion, it can be suggested that our microreactors can perform rapid digestion compared with in-solution digestion. 


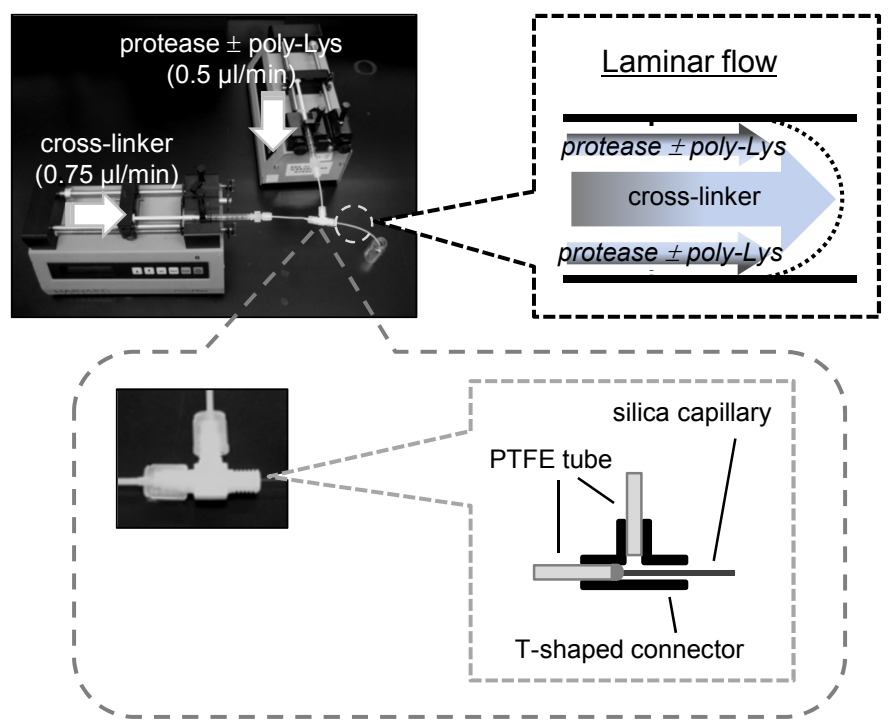

Fig. 1. The assembled microflow system for the preparation of protease-immobilized microreactor (Honda et al., 2006; Yamaguchi et al., 2009). The cross-linker solution was supplied to the substrate PTFE microtube through a silica capillary, corresponding to a central stream in the concentric laminar flow. A solution of proteases or a protease/poly-Lys mixture was supplied from another PTFE microtube connected to the T-shaped connector. Both solutions were introduced by syringe pumps.

In addition to these protease-immobilized microreactors, we also prepared alkaline phosphatase- (AP) immobilized microreactor for analysis of protein phosphorylation. Because the $\mathrm{pI}$ value of AP is 5.9, the poly-Lys supported immobilization procedure was used for the AP-immobilized microreactor. When high molecular weight of poly-Lys $(62 \mathrm{kDa})$ which was intended for CT-microreactor was used for the AP-microreactor, an aggregation of protein was readily observed, suggesting that high positively charged polyLys $(62 \mathrm{kDa})$ was quickly interacted with the acidic AP protein by electrostatic interaction. Because our enzyme-polymeric membrane is formed on the inner wall of the microchannel (500 $\mu \mathrm{m}$ inner diameter) through cross-linking polymerization in a laminar flow (Fig. 1), the quickly aggregated enzyme and poly-Lys can be stucked on the microchannel during crosslinking polymerization. Therefore, it is suggested that the large poly-Lys $(62 \mathrm{kDa})$ molecular is not appropriate for preparation of AP-microreactor. To overcome this problem, a low molecular weight poly-Lys $(4 \mathrm{kDa})$ was used for the polymerization of AP. As expected, with the use of poly-Lys $(4 \mathrm{kDa})$, quick aggregation was suppressed and AP-microreactor was successfully prepared.

\section{Characterization of the protease-immobilized microreactors}

\subsection{Kinetic characterization}

In our digestion procedure, the substrate solution was pumped through the microreactor using a syringe pump (Fig. 2A). A reaction time is correlated with a flow rate of the substrate. In the present microreactors, the hydrolysis reaction at a flow rate of $5.0 \mu \mathrm{l} / \mathrm{min}$ 

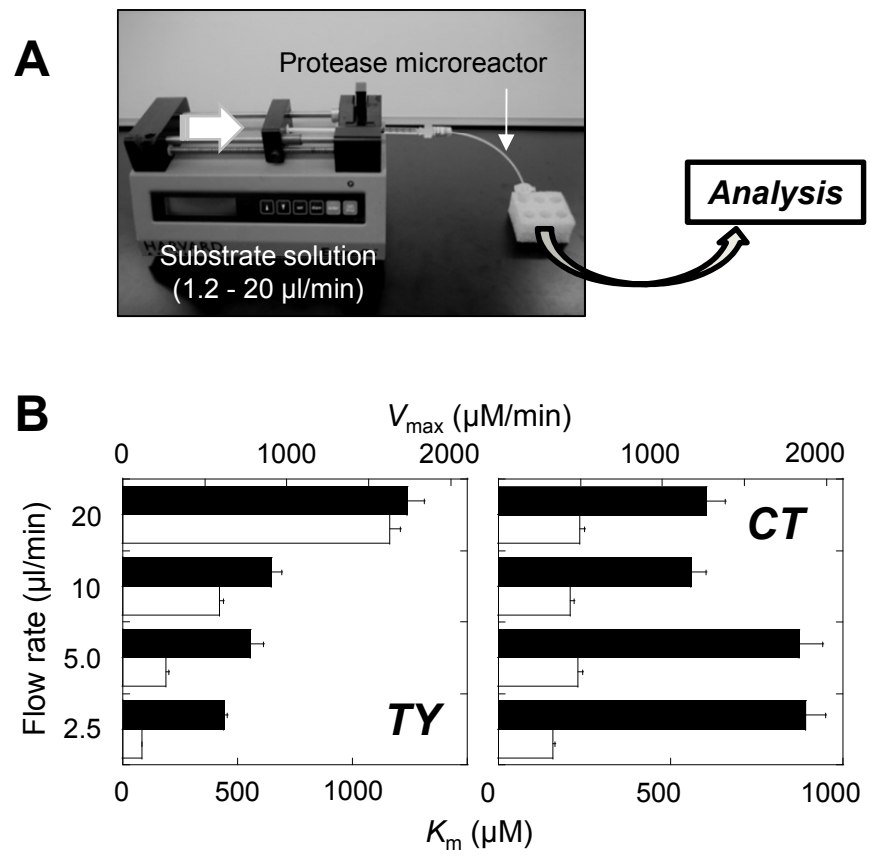

Fig. 2. (A) Schematic representation of the hydrolytic reaction by the protease-immobilized microreactor. Reaction temperature was kept in an incubator. (B) Kinetic parameters of hydrolysis activity of the protease-immobilized microreactors at different flow rates of the substrates. Substrates: BAPA for TY; GPNA for CT. Open bars, $K_{\mathrm{m}}(\mu \mathrm{M})$; closed bars, $V_{\max }$ $(\mu \mathrm{M} / \mathrm{min})$. The graph shows the mean \pm standard error for at least three experiments. All assays were performed in $50 \mathrm{mM}$ Tris $-\mathrm{HCl}\left(\mathrm{pH} \mathrm{8.0)}\right.$ at $30^{\circ} \mathrm{C}$.

yields a reaction time of $5.2 \mathrm{~min}$ (PTFE microtube volume of $26 \mu \mathrm{l}$ ). The individual hydrolysis activity of the microreactors was evaluated using synthetic small compounds; benzoyl-L-arginine $p$-nitroanilide (BAPA) for TY-microreactor and N-glutaryl-Lphenylalanine $p$-nitroanilide (GPNA) for CT-microreactor. Digestions by both microreactors showed a similar order of $K_{\mathrm{m}}$ values (hundred micromolar) to the reported $K_{\mathrm{m}}$ values for TY in a microtube (Yamashita et al., 2009) and CT-microreactor (Honda et al., 2005), suggesting that both immobilized proteases maintain their own hydrolysis activity after polymerization on PTFE surface.

It is known that the flow rate of substrate can affect the efficiency of the immobilized enzyme activity (Fan \& Chen, 2007; Honda et al., 2005; Ma et al., 2008; Nel et al., 2008; Wu et al., 2004; Dulay et al., 2005). Therefore, we studied the effect of different delivery speeds of substrates on hydrolysis activities (Yamaguchi et al., 2009). As shown in Fig. 2B, the estimated $K_{\mathrm{m}}$ values for TY-microreactor decreased with increase in flow rate, while no significant change in $K_{\mathrm{m}}$ values was observed for CT-microreactor at different flow rate, indicating that the diffusion limitation of the substrate in the immobilized TY is more influenced than that in the immobilized CT. Because both proteases have similar conformational structures and catalytic-sites as well-known, the difference between TYmicroreactor and CT-microreactor could be attributed to the difference in polymerization 
procedure. In contrast to $K_{\mathrm{m}}$ values, $V_{\max }$ values for both microreactors increased with increase in flow rate. Therefore, both microreactors showed higher $V_{\max } / K_{\mathrm{m}}$ values at lower flow rate (longer reaction time) but lower $V_{\max } / K_{\mathrm{m}}$ values at higher flow rate (shorter reaction time), suggesting that the hydrolysis activity was more efficient at lower flow rate. This indicates that efficient digestion of substrate by immobilized protease was achieved using an alternative substrate mobilization approach that involved incubation of substrate with immobilized enzyme. In contrast, the calculated $K_{\mathrm{m}}$ value for free TY was $806 \mu \mathrm{M}$, a $K_{\mathrm{m}}$ value that was 4.3 -fold higher than TY-microreactor with the same reaction time. Free CT also showed much higher $K_{\mathrm{m}}$ value (over $1 \mathrm{mM}$ ) compared with that of CTmicroreactor. It is known that $K_{\mathrm{m}}$ value represents the binding affinity between enzyme and substrate, and lower $K_{\mathrm{m}}$ value means higher affinity therefore, suggesting that the enhanced mass-transfer in the microchannel induced hydrolysis reaction (Honda et al., 2005; Honda et al., 2007).

\subsection{Operational stabilities of the protease-immobilized microreactors}

The operational stability and reusability of the protease-immobilized microreactor are important for its application in the proteomics analysis. Therefore, the stability of immobilized proteases against temperature in the hydrolysis reaction were tested (Yamaguchi et al., 2009). The relative hydrolysis activity against BAPA or GPNA of the protease-immobilized microreactors and free proteases at different temperatures were measured. The results showed that both immobilized proteases were more stable at high temperature than free proteases. At $50{ }^{\circ} \mathrm{C}$, free TY and free CT showed 15 and $52 \%$ of hydrolysis activities respectively, while the immobilized proteases kept at $30{ }^{\circ} \mathrm{C}$ retained their activities. It is suggested that due to multipoint interactions between the TY molecules or between CT and poly-Lys, the immobilized proteases increased the thermal stabilities of the enzymes. Similar thermal stability of immobilized enzyme was previously reported (Kim et al., 2009; Sheldon 2007).

Next, the stability of the protease-microreactors against high concentration of denaturant was tested. When the substrate solutions in $3 \mathrm{M}$ guanidine hydrochloride ( $\mathrm{Gdn}-\mathrm{HCl})$ were delivered to both protease-immobilized microreactors, we observed almost the same hydrolysis activities compared with those in buffer containing no denaturant. In contrast, free proteases in $3 \mathrm{M} \mathrm{Gdn}-\mathrm{HCl}$ were denaturated consequently and did not show any hydrolysis activities. Similar stability of CT-microreactor against $4 \mathrm{M}$ urea and $50 \%$ dimethyl sulfoxide were previously observed (Honda et al., 2005). Although both immobilized proteases did not show any hydrolysis activities in $5 \mathrm{M} \mathrm{Gdn}-\mathrm{HCl}$, over $90 \%$ recovered activities were observed after washing the microreactors with buffer containing no Gdn$\mathrm{HCl}$. Moreover, the reusability of the microreactors was also investigated by storing them at $\mathrm{pH} 8.0$ at $4{ }^{\circ} \mathrm{C}$. After over 60 days (after over 20 times reuse), both microreactors retained over $90 \%$ of their hydrolysis activities against synthetic substrates while free proteases had very little to no activities. More recently, the immobilized subtilisin by poly-Lys supported cross-linking was also more stable than free protease at high temperature, in the presence of a chemical denaturant or in an organic solvent and was recycled without appreciable loss of activity (Yamaguchi et al., 2011). These results indicate that the stability of proteases was improved after formation of enzyme-polymerization. This enhancement in the efficiency of activity of the immobilized protease compared to free protease can be ascribed to minimization or elimination of the auto-digestion of proteases (Dulay et al., 2005; Shui et al., 2006) and possible stabilization of the structure of proteases by cross-linking, thus resulting 
in higher accessibility of the substrate to the catalytic-site of the enzyme (Honda et al., 2005; Honda et al., 2006; Dulay et al., 2005; Shui et al., 2006).

The operational stability of the protease-immobilized microreactors was also tested based on the digestions of cytochrome $c(\mathrm{Cyt}-\mathrm{C})$ for TY-microreactor and $\beta$-casein for CT-microreactor (Yamaguchi et al., 2010a). Between each digestion, both microreactors were washed with buffer solution and stored at $4{ }^{\circ} \mathrm{C}$ for over 60 days. The obtained $10 \mathrm{MS}$ spectra (not shown) were identical with the similar sequence coverage of $93 \%$ (Cyt-C by TY-microreactor) and $57 \%$ ( $\beta$-casein by CT-microreactor). In contrast, free proteases almost completely lost their activities at $25^{\circ} \mathrm{C}$ within a couple of days, as reported previously (Sakai-Kato et al., 2002). These results indicate that the stability of proteases was increased by the prevention of autodigestion after an enzyme-immobilization.

\subsection{Proteolysis by the protease-immobilized microreactors}

Our previous proteolysis procedure using microreactors was carried out in $50 \mathrm{mM}$ Tris- $\mathrm{HCl}$ ( $\mathrm{pH}$ 8.0) solution (Yamaguchi et al., 2009). In this buffer system, an additional purification step using reversed-phase micropipette tips prior to MS measurement could remove excessive amounts of buffer salt, but could lead to sample losses especially of hydrophobic peptides due to their inherent affinity to reversed-phase surfaces, leading to lower sequence coverage. To avoid this, proteolysis was carried out in a $10 \mathrm{mM}$ ammonium acetate buffer ( $\mathrm{pH}$ 8.5) that easily evaporated during ESI-TOF MS measurement without the need for any desalting procedure. The digested peptides were collected in a test tube and then directly analyzed by ESI-TOF MS using Mariner mass spectrometer (Applied Biosystems Inc.) and reverse-phase high performance liquid chromatography (HPLC) (Yamaguchi et al, 2010a).

\begin{tabular}{|c|c|c|c|c|}
\hline $\begin{array}{c}\text { Digestion } \\
\text { methods }\end{array}$ & $\begin{array}{c}\text { Temperature } \\
/{ }^{\circ} \mathrm{C}\end{array}$ & Reaction time & $\begin{array}{c}\text { Identified } \\
\text { amino acids }\end{array}$ & $\begin{array}{c}\text { Sequence } \\
\text { coverage } / \%\end{array}$ \\
\hline TY-microreactor & 30 & $10.4 \mathrm{~min}$ & $97 / 104$ & 93 \\
\hline CT-microreactor & 30 & $10.4 \mathrm{~min}$ & $40 / 104$ & 38 \\
\hline TY (in-solution) ${ }^{a}$ & 37 & 18 hours & $99 / 104$ & 95 \\
\hline CT (in-solution) ${ }^{a}$ & 37 & 18 hours & $68 / 104$ & 65 \\
\hline
\end{tabular}

aIn-solution digestion was carried out in $10 \mathrm{mM}$ ammonium acetate buffer, $\mathrm{pH}$ 8.5. Concentrations of substrate and free proteases were 100 and $2 \mu \mathrm{g} / \mathrm{ml}$, respectively.

Table 1. Summary of ESI-TOF MS results of the digests of Cyt-C

To study the effect of flow rate on the proteolysis efficiency, we first investigated the digestion of Cyt-C by TY-microreactor at several flow rates. Under our experimental conditions, with flow rate increase from 1.2 to $15 \mu \mathrm{l} / \mathrm{min}$, auto-digestion peak of protease was not observed by MS and HPLC analyses. In addition, MALDI-TOF MS analysis using Bruker Autoflex (Bruker Daltonics) indicated that no free protease or cross-linked aggregation came off from the PTFE tubes, demonstrating good mechanical stability. Proteolysis was carried out at $30^{\circ} \mathrm{C}$. The digests by TY-microreactor were analyzed by ESITOF MS spectra and reverse-phase HPLC profiles. With a flow range of $2.5-15 \mu \mathrm{l} / \mathrm{min}$, the intact Cyt-C was observed while below $1.2 \mu \mathrm{l} / \mathrm{min}$ over $90 \%$ of Cyt-C was digested by TYmicroreactor. The results indicate that digestion at a lower flow rate (longer reaction time) is more efficient as shown in Fig. 2B (against small compound). Although intact Cyt-C remained in the samples above $2.5 \mu \mathrm{l} /$ min flow rate, the matched peptides covered $93 \%$ 
(97/104 amino acids) of the Cyt-C sequence (Table 1). This value was the same as that of the digested sample at $1.2 \mu \mathrm{l} / \mathrm{min}$. For comparison, in-solution digestions of Cyt-C with an incubation time of 18 hours at 30 and $37^{\circ} \mathrm{C}$ were performed. Although the reaction at $37^{\circ} \mathrm{C}$ showed complete digestion, only $40 \%$ Cyt-C was digested at $30{ }^{\circ} \mathrm{C}$, which is of the same proteolysis condition as that of the TY-microreactor. Thus, these results indicate that digestion of Cyt-C by TY-microreactor was much faster and efficient than in-solution digestion and that there is no need to perform the digestion at higher temperature. In contrast to TY-microreactor, CT-microreactor showed lower sequence coverage (38\%) than that by in-solution digestion $(65 \%)$. Because $\mathrm{Cyt}-\mathrm{C}$ was not denaturated by denaturant in this digestion condition, a possible reason for the lower digestion ability of CT-microreactor could be mass transfer limitation of folded Cyt-C in the cross-linked CT and poly-Lys complex matrix.

The residues of Lys and Arg which are recognized by TY, are hydrophilic residue that usually locate the surface of protein, while aromatic residues for CT are buried inside the protein. It is possible that immobilized TY could easily recognize the residues of Lys and Arg; on the other hand, immobilized CT could not interact with aromatic residues. As described above, the microreactors have stability against high concentration of denaturant and the denaturated Cyt-C with its aromatic residue exposed to the outside is expected to be digested by CT-microreactor. To confirm this possibility, Cyt-C digestion by CTmicroreactor was carried out in $3 \mathrm{M} \mathrm{Gdn}-\mathrm{HCl}$. Circular dichroism (CD) spectrum revealed that Cyt-C $(100 \mu \mathrm{g} / \mathrm{mL})$ in $3 \mathrm{M} \mathrm{Gdn}-\mathrm{HCl}$ was denaturated. Under this condition, free CT did not show any proteolysis activity. In contrast to in-solution digestion, the digests by CTmicroreactor showed a different HPLC profile compared with the HPLC profile of intact Cyt-C in $3 \mathrm{M} \mathrm{Gdn}-\mathrm{HCl}$, indicating that the immobilized $\mathrm{CT}$ in $3 \mathrm{M} \mathrm{Gdn}-\mathrm{HCl}$ digested the denaturated Cyt-C (Yamaguchi et al., 2009). Furthermore, MS analysis of the digests also showed the efficient digestion by CT-microreactor in $3 \mathrm{M} \mathrm{Gdn}-\mathrm{HCl}$. These results suggest that the stability of immobilized proteases is superior to that of free proteases.

A typical sample preparation for proteolysis before digestion involves multi-steps including denaturation, reduction of disulfide bond, and alkylation of free thiol group to reduce the conformational stability of protein; steps which are expected to produce enhancement of digestion efficiency (Ma et al., 2008; Li et al., 2007a; Ethier et al., 2006; Lin et al., 2008). However, the multi-step procedure is time-consuming. In contrast, our digestion method by protease-immobilized microreactor can be carried out with high concentration of denaturant and high sequence coverage. Moreover, it can directly use the denaturated protein as a substrate. In addition, it does not need any complicated reduction and alkylation steps, therefore, exhibiting superior advantages of our digestion procedure over other reported protease-immobilized microreactor in achieving rapid proteomics analysis.

\subsection{Proteolysis by the tandem protease-immobilized microreactors}

The improved sequence coverage is important to enhance the probability of identification and increase the likelihood of detection of structural variants generated by processes such as alternative splicing and post-translational modifications. The identification of the protein sequence is a first and important step in proteome analysis. Post-translational modification such as phosphorylation is also important information in understanding the role of target protein in the regulation of fundamental cellular processes. Because disregulations of mechanisms of modifications are implicated in various diseases, including cancer (Hunter, 2009), the characterization of protein sequence is useful for biological and clinical researches. 
The conventional approach using multi-digestion by different proteases for improved sequence coverage is based on parallel digestions of the same samples and analyzes overlapping peptides. However, this approach takes long time and multi-step procedure. To overcome this difficulty, we prepared the tandem microreactor that was connected by different protease-immobilized microreactors using a Teflon connector. Connection was made easy because the present microreactors were made of PTFE microtube. It is expected that the combination of MS results obtained with the tandem microreactor that carries out multi-digestion may give significantly higher sequence coverage than that obtained with individual digestion by the single microreactor. Based on a similar idea, a reactor which was a bonded mixture of TY and CT to an epoxy monolithic silica column was reported (Temporini et al., 2009). In contrast to the mixture of TY and CT immobilized reactor (Temporini et al., 2009), an interesting feature of our microreactor is the ease in linking each microreactor by using a connector. In our system, we can easily change the order of each microreactor (for example, CT-TY or TY-CT) according to our preference (Yamaguchi et al., 2010a).

Cyt-C (non-phosphoprotein), $\beta$-casein (phosphoprotein) and pepsin A (phosphoprotein) were used to test the performance of the tandem microreactors. The enzymatic reaction at a flow rate of $2.5 \mu \mathrm{l} / \mathrm{min}$ yielded a reaction time of $10.4 \mathrm{~min}$ (single microreactor) or $20.8 \mathrm{~min}$ (tandem microreactor). The digestion efficiency by the microreactors was evaluated by analyzing the sequence coverage and the identified peptide. Some of the digested peptides by the microreactors were the expected peptides that have one or two missed cleavage site. The $\mathrm{p} I$ value of Cyt-C is 9.6 (horse residue 2-104), suggesting that Arg or Lys residues locate the protein surface with high possibility. As shown above, Cyt-C was digested by TYmicroreactor with higher sequence coverage $(93 \%$ in Table 1$)$ at $30{ }^{\circ} \mathrm{C}$. MALDI-TOF MS analysis also showed high sequence coverage $(89 \%)$. The value of sequence coverage was higher than the other trypsin-immobilized reactors reported (Li et al., 2007a; Liu et al., 2009) and the same as that performed by in-solution digestion $\left(37^{\circ} \mathrm{C}\right.$ for 18 hours), suggesting that the immobilized TY showed rapid and efficient proteolysis.

The multi-digestion of Cyt-C by the tandem microreactor that was connected by using TYmicroreactor and CT-microreactor was evaluated. TY-CT tandem microreactor also showed rapid Cyt-C digestion with the similar sequence coverage as that of the single TYmicroreactor. As expected, the multi-digested peptides such as VQK, TGPNLHGLF or TGQAPGF were identified (Yamaguchi et al., 2010a). Because some digested peptides $(<300$ Da) by tandem microreactor were too small to be identified by TOF-MS analysis, therefore based on comparison with the single TY microreactor the sequence coverage for Cyt-C by the tandem microreactor was found not to improve (88\%, 91/104 amino acids). These results indicate that the peptide fragments by TY-microreactor were also digested by CTmicroreactor, as expected.

Bovine $\beta$-casein (residue 16-224) is a phosphoprotein with well-characterized phosphorylated sites (Han et al., 2009; Li et al., 2007b). MS measurement of an intact protein revealed that $\beta$-casein in this study has five phosphorylated sites. By measuring the decrease in the peak area at $220 \mathrm{~nm}$ of HPLC profiles of the digests, it could be estimated that over $90 \% \beta$-casein was digested by CT-microreactor for $10.4 \mathrm{~min}$ at $30{ }^{\circ} \mathrm{C}$. ESI-TOF MS analysis revealed that 13 peptides containing 120 out of the 209 possible amino acids of $\beta$-casein were obtained, producing the sequence coverage of 57\% (Yamaguchi et al., 2010a). This value was higher than that by in-solution digestion (45\%, 95/209 amino acids). Moreover, the 
phosphopeptide containing four phosphoserine (pS) residues (pSpSpSEEpSITRINKKIEKF) was detected despite the low ionization efficiency of the phosphopeptide. To confirm this detection of the phosphopeptide by other MS system, MALDI-TOF MS analysis was performed. In addition to the pSpSpSEEpSITRINKKIEKF phosphopeptide, the QpSEEQQQTEDEL phosphopeptide was also identified by MALDI-TOF MS analysis, thereby showing that all phosphorylation sites on $\beta$-casein in this study were detected from the digests by CT-microreactor. In contrast, HPLC analysis of digested $\beta$-casein by TYmicroreactor showed a broad profile and was different with that by CT-microreactor. In addition to the $\mathrm{p} I$ value of $\beta$-casein (5.1) that was estimated from the primary structure and which did not take into account the number of phosphorylation sites, the total number of Phe, Trp, Tyr, Leu and Met residues (42) was larger than that of Arg and Lys residues (15). Therefore, it is suggested that the sequence coverage of $\beta$-casein by TY-microreactor $(14 \%)$ or in-solution digestion by free trypsin $(21 \%)$ is lower than that by CT-microreactor. We next studied the feasibility of enzyme-immobilized tandem microreactor. As expected, the multidigestion by CT-TY tandem microreactor showed 20 digested peptides (Yamaguchi et al., 2010a). It is noteworthy that GVSK, VKEAMAPK, HKEMPFPK and YPVEPF peptides that were not identified by the single CT-microreactor were identified by the tandem microreactor. The results indicate that an improvement of the sequence coverage in digestion by tandem microreactor in comparison to the single microreactor and in-solution digestion can be expected.

\subsection{Phosphorylation site analysis by the tandem microreactor}

Further analysis of protein phosphorylation was carried out using AP-microreactor. HPLC profile of the digested peptides by CT-AP tandem microreactor revealed the disappearance of two peaks compared to that by the single CT-microreactor. This suggested that the phosphopeptides containing pSpSpSEEpSITRINKKIEKF were dephosphorylated by AP. MS analysis also revealed the dephosphorylation of the pSpSpSEEpSITRINKKIEKF phosphopeptide. The results indicate that the tandem microreactor which was made by using the protease-microreactor and the phosphatase-microreactor showed the feasibility of the identification of phosphorylation site in phosphoproteins without any enrichment strategies and radioisotope labeling. $\beta$-Casein has another well-known phosphorylated site (Ser35). Because the phosphopeptide containing Ser35 (QpSEEQQQTEDEL) was detected by MALDI-TOF MS analysis, it is possible that the one peak that disappeared in HPLC profile may be the phosphopeptide containing pS35.

Pepsin A (porcine residue 60-385) is an acidic protease ( $\mathrm{pI}$ of 3.2) and a phosphoprotein which has one phosphoserine residue (Kinoshita et al., 2006). An optimum pH of pepsin A for its protease activity is around 2.0, meaning that pepsin A does not have any activity under our digestion condition at $\mathrm{pH}$ 8.5. Therefore, pepsin $\mathrm{A}$ was used as a substrate without any denaturation procedure. Similar to the digestion of $\beta$-casein, pepsin A was efficiently digested by CT-microreactor but not by TY-microreactor thus, explaining the difference between the total number of cleavage sites by CT ( 65 residues) and those by TY ( 3 residues). The sequence coverage of 55\% (179/326 amino acids) by CT-microreactor was lower than that by in-solution digestion (60\%, 196/326 amino acids) (Yamaguchi et al., 2010a). In addition, the phosphopeptide (EATpSQELSITY) was detected in the digestion by in-solution but not by CT-microreactor. When HPLC profile of the digests by the single CTmicroreactor was compared with CT-AP tandem microreactor digest, it was found out that 
one peak disappeared after passing through the tandem microreactor. This suggests that the digests by CT-microreactor also contain the phosphopeptide but the size of the peptide was bigger than the EATpSQELSITY phosphopeptide from in-solution digestion. In addition, it is possible that our MS system was not able to detect the phosphopeptide from CTmicroreactor. A possible reason for the lower digestion ability of CT-microreactor could be mass transfer limitation of folded pepsin A in the cross-linked CT and poly-Lys complex matrix. Similar lower digestion ability of the immobilized-protease was observed in the digestion of Cyt-C by CT-microreactor as described above.

The present analytical method of protein phosphorylation is much simpler than the other conventional methods (Han et al., 2009; Kinoshita et al., 2006; Zhao \& Jensen, 2009), for example, the phosphoprotein is just flowed through the microreactor and it eliminates purification of digests from the reaction system without any enrichment strategies. These interesting features are superior advantages of our approach using the enzyme-immobilized microreactors over the conventional method.

\subsection{Analysis of disulfide bond using the protease-immobilized microreactor at several temperatures}

Disulfide bond is covalent cross-linking between side-chains of two Cys residues of the same or different peptide chains. It is an important factor for stabilizing the protein conformation. In addition, oxidation-reduction of Cys residues in protein is significant to biological functions (Lee et al., 2004; Mieyal et al., 2008; Yano \& Kuroda, 2008). Therefore, the assignment of disulfide bonding patterns will not only provide insights into its threedimensional structure and contribute to the understanding of its structure-function relationship but will also play a role in the regulation of fundamental cellular processes. However, the conventional method for the assignment of disulfide bond by chemical cleavage and/or proteolysis is a time-consuming multi-step procedure. In addition, due to higher conformational stability of protein by disulfide bond(s), the conventional in-solution digestion by protease was usually carried out using reduced protein which was prepared by the reduction and alkylation procedure. Although this approach has provided us with information on the protein sequence (primary structure of protein), the information for disulfide bond such as Cys-Cys pair(s), the number of disulfide bond, and a distinction between Cys residues involving disulfide bond and free Cys residue are not from the conventional reduced sample.

As shown above, the protease-immobilized microreactor showed a rapid and efficient digestion compared with in-solution digestion. Furthermore, the immobilized-protease can be easily isolated and removed from the digests prior to MS without any purification step. Moreover, the immobilized proteases by our methods were more stable at high temperature than free proteases (Yamaguchi et al., 2009). Based on these interesting features, we tested whether the substrate proteins that maintain their disulfide bonds can be efficiently digested by the protease-immobilized microreactor at high temperature without any chemical modification and purification step, and whether the position of disulfide bond(s) in the resultant digests can be analyzed by MS (Yamaguchi et al., 2010b).

It was reported that thermally denatured proteins were efficiently digested by in-solution digestion (Park \& Russell, 2000) or by protease-microreactors using free proteases (Liu et al., 2009; Sim et al., 2006). Our approach is based on the concept that proteins of stable conformation owing to their disulfide bonds(s) were thermally denatured at high 
temperature and were directly digested by the protease-immobilized microreactor. It is known that thermal denaturation at higher temperature $\left(\sim 90{ }^{\circ} \mathrm{C}\right)$ would form the protein aggregation (Park \& Russell, 2000) although the mechanism of this formation has not yet been fully elucidated. Therefore, we performed the proteolysis between 30 to $50{ }^{\circ} \mathrm{C}$. Substrate proteins $(50 \mu \mathrm{g} / \mathrm{ml})$ which were not treated with the reduction and alkylation procedure were pumped through the microreactor at flow rate of $1.2 \mu \mathrm{l} / \mathrm{min}$ (reaction time: $21.7 \mathrm{~min}$ ). The digests were collected in a test-tube and directly analyzed by ESI-TOF MS without any purification or concentration procedure.

Lysozyme (chicken residue 19-147: MW 14,304 Da) has well-characterized four disulfide bonds. As shown in Fig. 3, the digests by both microreactors showed that increasing reaction temperature increased the number of digested fragments, which were correlated with the sequence coverage (Table 2). Most of the digested peptides by the microreactors were the expected peptides which did not have the missed cleavage site. At $50{ }^{\circ} \mathrm{C}$ by $\mathrm{TY}$ microreactor, 10 peptides containing 126 out of the 129 possible amino acids of lysozyme were obtained, producing the sequence coverage of $98 \%$. This value was higher than those by TY-microreactor at $30{ }^{\circ} \mathrm{C}\left(5 \%, 7 / 129\right.$ amino acids) and in-solution digestion at $37{ }^{\circ} \mathrm{C}$ (77\%, 99/129 amino acids). Moreover, all four disulfide bonds (Cys24-Cys145, Cys48Cys133, Cys83-Cys98, and Cys94-Cys112) were detected in MS spectrum from the digests at $50{ }^{\circ} \mathrm{C}$ but 3 of 4 disulfide bonds (Cys48-Cys133, Cys83-Cys98, and Cys94-Cys112) were from in-solution digestion at $37{ }^{\circ} \mathrm{C}$ (Yamaguchi et al., 2010b). The sequence coverage of $22 \%$ $(28 / 129)$ by the TY-microreactor at $40{ }^{\circ} \mathrm{C}$ was lower than that by in-solution digestion at $37^{\circ} \mathrm{C}$. A possible reason for the lower digestion ability of TY-microreactor could be that the substrate protein has different exposure of the digestion site by TY between in the microchannel and in batch method (in-solution digestion).

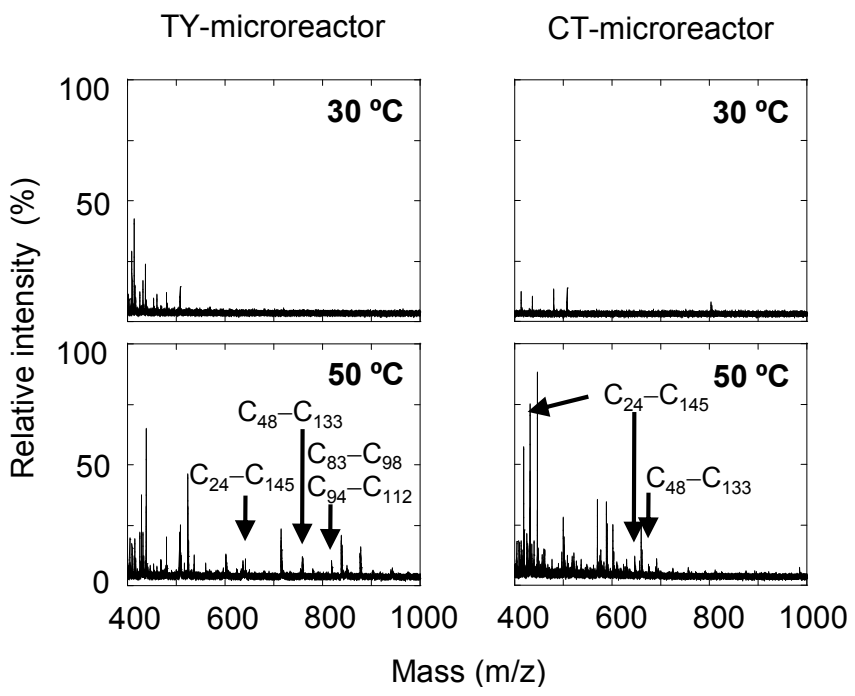

Fig. 3. ESI-TOF MS spectra of the digests of lysozyme by TY- or CT-microreactor. Digestion was carried out at different temperature: 30 and $50{ }^{\circ} \mathrm{C}$. The peaks of disulfide bond(s)containing peptides are marked with solid arrows. 


\begin{tabular}{|c|c|c|c|c|}
\hline $\begin{array}{c}\text { Digestion } \\
\text { methods }\end{array}$ & $\begin{array}{c}\text { Temperature / } \\
{ }^{\circ} \mathrm{C}\end{array}$ & Reaction time & $\begin{array}{c}\text { Identified } \\
\text { amino acids }\end{array}$ & $\begin{array}{c}\text { Sequence } \\
\text { coverage / \% }\end{array}$ \\
\hline TY-microreactor & 30 & $21.7 \mathrm{~min}$ & $7 / 129$ & 5 \\
\hline TY-microreactor & 50 & $21.7 \mathrm{~min}$ & $126 / 129$ & 98 \\
\hline CT-microreactor & 30 & $21.7 \mathrm{~min}$ & $11 / 129$ & 9 \\
\hline CT-microreactor & 50 & $21.7 \mathrm{~min}$ & $54 / 129$ & 42 \\
\hline TY (in-solution) ${ }^{a}$ & 37 & 18 hours & $99 / 129$ & 77 \\
\hline CT (in-solution) ${ }^{a}$ & 37 & 18 hours & $66 / 129$ & 51 \\
\hline
\end{tabular}

${ }^{a}$ In-solution digestion was carried out in $10 \mathrm{mM}$ ammonium acetate buffer, $\mathrm{pH}$ 8.5. Concentrations of substrate and free proteases were 100 and $2 \mu \mathrm{g} / \mathrm{ml}$, respectively.

Table 2. Summary of ESI-TOF MS results of the digests of lysozyme

In contrast, sequence coverage by CT-microreactor at $50{ }^{\circ} \mathrm{C}$ and in-solution digestion at $37^{\circ} \mathrm{C}$ by free CT were lower than that by TY-microreactor (Table 2), although the total number of Phe, Trp, Tyr, Leu, and Met residues (22) for CT was larger than that of Arg and Lys residues (17) for TY. CD and fluorescence spectra measurements indicated that lysozyme at $50{ }^{\circ} \mathrm{C}$ was thermally denatured but partly formed some secondary structures. Basic residues are usually located on the surface of protein than hydrophobic residues. In addition, the $\mathrm{pI}$ value of lysozyme is 9.3. Therefore, it is possible that TY easily recognizes and hydrolyses peptide bonds after Arg and Lys residues that locate on the surface of lysozyme. Because sequence coverage by CT was lower than that by TY, the number of identified disulfide bonds was also low. The sequence coverage of lysozyme by in-solution digestion at $50{ }^{\circ} \mathrm{C}(18 \%$ for free TY and $22 \%$ for free CT) were lower than those by the microreactors at $50{ }^{\circ} \mathrm{C}$, indicating that free proteases decreased their hydrolysis activities at $50^{\circ} \mathrm{C}$.

To further investigate the efficiency of our approach for the assignment of disulfide bond, the digestion of bovine serum albumin (BSA) by the microreactor was carried out (Yamaguchi et al., 2010b). BSA (bovine residue 25-607: MW 66,390 Da) has 17 disulfide bonds. Similar to the digestion of lysozyme, the digestion of BSA by TY-microreactor at $50{ }^{\circ} \mathrm{C}$ efficiently occurred but not at $30^{\circ} \mathrm{C}$. The sequence coverage of $37 \%$ (201/583 amino acids) was higher compared with that of in-solution digestion $(26 \%, 151 / 583$ amino acids) and was better or comparable to those of a thermal (Liu et al., 2009; Sim et al., 2006) or chemical denatured BSA (Li et al., 2007a; Chatterjee et al., 2010) or the reduced BSA (Ma et al., 2008) by the reported trypsin-microreactors (24-46\%). In addition, the number of identified disulfide bonds was 10 of 17, which is superior to 6 obtained by in-solution digestion. The digests of BSA by the TY-microreactor at $50{ }^{\circ} \mathrm{C}$ was also analyzed by MALDITOF MS. In addition to the information on disulfide bonds from ESI-TOF MS, we identified the TCVADESHAGCEK peptide with intramolecular disulfide bond (Cys77-Cys86) that was not identified by ESI-TOF MS. Although all disulfide bonds in BSA were not identified under the present condition, these results indicate that proteolysis approach at high temperature by the microreactors can be useful not only for large proteins but also for the proteins having many disulfide bonds. After each proteolysis procedure at several temperatures, the microreactors were washed with buffer solution and digestions were carried out at $30^{\circ} \mathrm{C}$. The residual activities of both microreactors after proteolysis procedure even at $50{ }^{\circ} \mathrm{C}$ were identical with those of prior to proteolysis, indicating that both immobilized proteases maintained their activities after several use at different temperatures. We also tested the hydrolysis activity of TY-microreactor against Cyt-C. MS spectra of Cyt-C 
by TY-microreactor before and after proteolysis at $50{ }^{\circ} \mathrm{C}$ were the same. In addition, both sequence coverage of Cyt-C by TY-microreactor were $89 \%$ (93/104 amino acids). This value was higher than those of the reported trypsin-immobilized reactors (Liu et al., 2007a; Liu et al., 2009). In contrast, free proteases showed lower proteolysis activities at $50{ }^{\circ} \mathrm{C}$ than those at $37{ }^{\circ} \mathrm{C}$. Once again, these results verified that the present protease-immobilized microreactors were thermally stable at high temperature but this was not observed in the case of free proteases. Similar stability of immobilized TY on polymer nanofibers was previously reported (Kim et al., 2009).

From these results, the procedures of proteolysis by the microreactor and the MS measurement took less than 2 hours. This is much faster and easier than the conventional procedure (multi-days). Therefore, our proteolysis approach by the thermostable microreactor is a simple and rapid analytical method for the assignment of disulfide bond without any chemical modification or purification procedure.

\section{Conclusion}

The microreactors showed efficient proteolysis with high sequence coverage, long-term stability, and good reusability. It is known that in-solution digestion by trypsin can induce artificial modifications such as asparagine deamidation (Krokhin et al., 2006) and N-terminal glutamine cyclization (Bongers et al., 1992; Dick et al., 2007) on target protein due to the elevated temperature and alkaline $\mathrm{pH}$ buffers used during digestion for overnight. Proteolysis by our protease-immobilized microreactors was achieved within a short period of time $(\sim 20 \mathrm{~min})$ at $30{ }^{\circ} \mathrm{C}$ therefore suggesting these artificial modifications as a remote possibility. In addtion, proteolysis by the tandem microreactors showed higher sequence coverage, which is a remarkable result compared with those of the single microreactor or insolution digestion. The tandem microreactor comprising a protease-microreactor and a phosphatase-microreactor also showed the capability to localize phosphorylation site(s) in phosphoproteins. Several protease-immobilized microreactors were developed for proteolysis. Most of these studies have focused on rapid digestion and reduction of sample volume. So far, there is no study yet on multi-enzymatic reaction system and analysis of post-translational modification in protein. Furthermore, proteolysis at $50{ }^{\circ} \mathrm{C}$ by the microreactors showed higher sequence coverage and assignment of disulfide bonds, which is a remarkable result compared with that of in-solution digestion.

The present procedure is much simpler than the other conventional methods, for example, the protein is just flowed through the microreactor and it is not necessary to purify the digests from the reaction system. These interesting features are superior advantages of our proteolysis approach over the conventional method. The enzyme-immobilization method using poly-Lys can be applied to proteins with wide-range $\mathrm{pI}$ values hence, the strategy based on multi-enzymatic reaction using the tandem microreactor provides a useful approach for other post-translational modification analysis (e.g. acetylation, methylation, ubiquitination or glycosylation). Coupling the protease-immibilized microreactor with MS and/or HPLC (on-line) can be also applied for high throughput proteomic analysis systems.

\section{Acknowledgment}

This work was supported by Grant-in-Aid for Basic Scientific Research (B: 23310092) and for Young Scientists (B: 23710153), from the Japan Society for the Promotion of Science (JSPS). 


\section{References}

Aebersold, R. \& Mann, M. (2003) Mass spectrometry-based proteomics. Nature, 422, 198-207.

Asanomi, Y., Yamaguchi, H., Miyazaki M. \& Maeda, H. (2011) Enzyme-immobilized microfluidic process reactors. Molecules, 16, 6041-6059.

Bongers, J., Heimer, E. P., Lambros, T., Pan, Y. C., Campbell, R. M. \& Felix, A. M. (1992) Degradation of aspartic acid and asparagines residues in human growth hormonereleasing factor. Int. J. Pept. Protein Res., 39, 364-374.

Chatterjee, D., Ytterberg, A. J., Son, S. U., Loo, J. A. \& Garrell, R. L. (2010) Integration of protein processing steps on a droplet microfluidics platform for MALDI-MS analysis. Anal. Chem., 82, 2095-2101.

Chen, W. Y. \& Chen Y. C. (2007) Acceleration of microwave-assisted enzymatic digestion reactions by magnetite beads. Anal. Chem., 79, 2394-2401.

Dick Jr., L. W., Kim, C., Qiu, D. \& Cheng, K. C. (2007) Determination of the origin of the Nterminal pyro-glutamate variation in monoclonal antibodies using model peptides. Biotechnol. Bioeng. 97, 544-553.

Domon, B. \& Aebersold, R. (2006) Mass spectrometry and protein analysis. Science, 312, 212217.

Dulay, M. T., Baca, Q. J. \& Zare, R. N. (2005) Enhanced proteolytic activity of covalently bound enzymes in photopolymerized sol gel . Anal. Chem., 77, 4604-4610.

Ethier M., Hou, W., Duewel, H. S. \& Figeys, D. (2006) The proteomic reactor: a microfluidic device for processing minute amounts of protein prior to mass spectrometry analysis. J. Proteomie Res., 5, 2754-2759.

Fan, H. \& Chen, G. (2007) Fiber-packed channel bioreactor for microfluidic protein digestion. Proteomics, 7, 3445-3449.

Fischer, F. \& Poetsch, A. (2006) Protein cleavage strategies for an improved analysis of the membrane proteome. Proteome Sci, 4, 2.

Han, G., Ye, M., Jiang, X., Chen, R., Ren, J., Xue, Y., Wang, F., Song, C., Yao, X. \& Zou, H. (2009) Comprehensive and reliable phosphorylation site mapping of individual phosphoproteins by combination of multiple stage mass spectrometric analysis with a target-decoy database search. Anal. Chem., 81, 5794-5805.

Honda, T., Miyazaki, M., Nakamura, H. \& Maeda, H. (2005) Immobilization of enzymes on a microchannel surface through cross-linking polymerization. Chem. Commun., 50625064.

Honda, T., Miyazaki, M., Nakamura, H. \& Maeda, H. (2006) Facile preparation of an enzyme-immobilized microreactor using a cross-linking enzyme membrane on a microchannel surface. Adv. Synth. Catal. 348, 2163-2171.

Honda, T., Miyazaki, M., Yamaguchi, Y., Nakamura, H. \& Maeda, H. (2007) Integrated microreaction system for optical resolution of racemic amino acids. Lab. Chip., 7, 366-372.

Hunter, T. (2009) Tyrosine phosphorylation: thirty years and counting. Curr. Opin. Cell Biol., 21, 140-146.

Kim, B. C., Lopez-Ferrer, D., Lee, S. -M., Ahn, H. -K., Nair, S., Kim, S. H., Kim, B. S., Petritis, K., Camp, D. G., Grate, J. W., Smith, R. D., Koo, Y. M., Gu, M. B. \& Kim, J. (2009) Highly stable trypsin-aggregate coatings on polymer nanofibers for repeated protein digestion. Proteomics, 9, 1893-1900. 
Kinoshita, E., Kinoshita-Kikuta, E., Takiyama, K. \& Koike, T. (2006) Phosphate-binding tag, a new tool to visualize phosphorylated proteins. Mol. Cell. Proteomics, 5, 749-757.

Krokhin, O. V., Antonovici, M., Ens, W., Wilkins, J. A. \& Standing, K. G. (2006) Deamidation of -Asn-Gly- sequences during sample preparation for proteomics: Consequence for MALDI and HPLC-MALDI analysis. Anal. Chem., 78, 6645-6650.

Lee, K., Lee, J., Kim, Y., Bae, D., Kang, K. Y., Yoon, S. C. \& Lim, D. (2004) Defining the plant disulfide proteome. Electrophoresis, 25, 532-541.

Lee, J., Musyimi, H. K., Soper, S. A. \& Murray, K. K. (2008) Development of an automated digestion and droplet deposition microfluidic chip for MALDI-TOF MS. J. Am. Soc. Mass Spectrom., 19, 964-972.

Li, Y., Xu, X. Q., Deng, C. H., Yang, P. Y. \& Zhang, X. M. (2007a) Immobilization of trypsin on superparamagnetic nanoparticles for rapid and effective proteolysis. J. Proteome Res., 6, 3849-3855.

Li, Y., Xu, X., Qi, D., Deng, C., Yang, P. \& Zhang, X. (2007b) Novel Fe $\mathrm{O}_{4} @ \mathrm{TiO}_{2}$ core-shell microspheres for selective enrichment of phosphopeptides in phosphoproteome analysis. J. Proteome Res., 7, 2526-2538.

Lin, S., Yao G., Qi, D., Li, Y., Deng, C., Yang, P. \& Zhang X. (2008) Fast and efficient proteolysis by microwave-assisted protein digestion using trypsin-immobilized magnetic silica microspheres. Anal. Chem., 80, 3655-3665.

Liu, Y., Lu, H., Zhong, W., Song, P., Kong, J., Yang, P., Girault, H. H. \& Liu B. (2006) Anal. Chem., 78, 801-808.

Liu, Y., Liu, B., Yang, P. \& Girault, H. H., (2008) Microfluidic enzymatic reactors for proteome research. Anal. Bioanal. Chem., 390, 227-229.

Liu, T., Bao, H., Zhang, L. \& Chen, G. (2009) Integration of electrodes in a suction cup-driven microchip for alternating current-accelerated proteolysis. Electrophoresis, 30, 32653268.

Ma, J., Ziang, Z., Qiao, X., Deng, Q., Tao, D., Zhang L. \& Zhang, Y. (2008) Organic-inorganic hybrid silica monolith based immobilized trypsin reactor with high enzymatic activity. Anal. Chem., 80, 2949-2956.

Ma, J., Zhang, L., Liang, Z., Zhang, W. \& Zhang, Y. (2009) Recent advance in immobilized enzymatic reactors and their applications in proteome analysis. Anal. Chim. Acta, 632, 1-8.

Mieyal, J. J., Gallogly, M. M., Qanungo, S., Sabens, E. A. \& Shelton, M. D. (2008) Molecular mechanisms and clinical implications of reversible protein S-glutathionylation. Antioxid. Redox Signal., 10, 1941-1988.

Miyazaki M. \& Maeda H. (2006) Microchannel enzyme reactors and their applications for processing. Trends Biotechnol., 24, 463-470.

Miyazaki, M., Honda, T., Yamaguchi, H., Briones, M. P. P. \& Maeda, H. (2008) Enzymatic processing in microfluidic reactors., Biotechnol. Genet. Eng. Rev., 25, 405-428.

Nel, A. L., Krenkova, J., Kleparnik, K., Smadja, C., Taverna, M., Viovy, J. L. \& Foret, F. (2008) On-chip tryptic digest with direct coupling to ESI-MS using magnetic particles. Electrophoresis, 29, 4944-4947.

Park Z. Y. \& Russell D. H. (2000) Thermal denaturation: A useful technique in peptide mass mapping. Anal. Chem., 72, 2667-2670. 
Sakai-Kato, K., Kato, M. \& Toyooka, T. (2002) On-line trypsin-encapsulated enzyme reactor by the sol-gel method integrated into capillary electrophoresis. Anal. Chem., 74, 2943-2949.

Sakai-Kato, K., Kato M. \& Toyooka, T. (2003) Creation of an on-chip enzyme reactor by encapsulating trypsin in sol-gel on a plastic microchip. Anal. Chem., 75, 388-393.

Sheldon R. A. (2007) Enzyme immobilization: The quest for optimum performance. Adv. Synth. Catal. 349, 1289-1307.

Sim, T. S., Kim, E. -M., Joo, H. S., Kim, B. G. \& Kim, Y. -K. (2006) Application of a temperature-controllable microreactor to simple and rapid protein identification using MALDI-TOF MS. Lab. Chip, 6, 1056-1061.

Slysz, G. W., Lewis, D. F. \& Schriemer, D. C. (2006) Detection and identification of subnanogram levels of protein in nanoLC-trypsin-MS system. J. Proteome Res., 5, 19591966.

Shui, W., Fan, J, Yang, P., Liu, C., Zhai, J., Lei, J., Yan, Y., Zhao, D. \& Chen, X. (2006) Nanopore-based proteolytic reactor for sensitive and comprehensive proteomic analyses. Anal. Chem., 78, 4811-4819.

Temporini, C., Calleri, E., Cabrera, K., Felix, G. \& Massolini, G. (2009) On-line multienzymatic approach for improved sequence coverage in protein analysis. J. Sep. Sci. $32,1120-1128$.

Wang, L. S., Khan, F. \& Micklefield, J. (2009) Selective covalent protein immobilization: strategies and applications. Chem. Rev., 109, 4025-4053.

Witze, E. S., Old, W. N., Resing, K. A. \& Ahn, N. G. (2007) Mapping protein posttranslational modifications with mass spectrometry. Nat. Methods, 10, 798-806.

Wu H., Tian Y., Liu, B., Lu, H., Wang, X., Zhai, J., Jin, H., Yang, P., Xu, Y. \& Wang H. (2004) Titania and alumina sol-gel-derived microfluidics enzymatic-reactors for peptide mapping: design, characterization, and performance. J. Proteome Res., 3, 1201-1209.

Yamaguchi, H., Miyazaki, M., Honda, T., Briones-Nagata, M. P., Arima, K. \& Maeda, H. (2009) Rapid and efficient proteolysis for proteomic analysis by proteaseimmobilized microreactor. Electrophoresis, 30, 3257-3264.

Yamaguchi, H., Miyazaki, M., Kawazumi, H. \& Maeda, H. (2010a) Multidigestion in continuous flow tandem protease-immobilized microreactors for proteomic analysis. Anal. Biochem., 407, 12-18.

Yamaguchi, H., Miyazaki, M. \& Maeda, H. (2010b) Proteolysis approach without chemical modification for a simple and rapid analysis of disulfide bonds using thermostable protease-immobilized microreactors. Proteomics, 10, 2942-2949.

Yamaguchi, H., Miyazaki, M., Asanomi Y. \& Maeda, H. (2011) Poly-lysine supported crosslinked enzyme aggregates with efficient enzymatic activity and high operational stability. Catal. Sci. Technol., DOI: 10.1039/c1cy00084e.

Yamashita, K., Miyazaki, M., Nakamura, H. \& Maeda, H. (2009) Nonimmobilized enzyme kinetics that rely on laminar flow. J. Phys. Chem. A, 113, 165-169.

Yano, H. \& Kuroda, S. (2008) Introduction of the disulfide proteome: Application of a technique for the analysis of plant storage proteins as well as allergens. J. Proteome Res., 7, 3071-3079. 
Zhao, Y. \& Jensen, O. N. (2009) Modification-specific proteomics: strategies for characterization of post-translational modifications using enrichment techniques. Proteomics, 9, 4632-4641. 


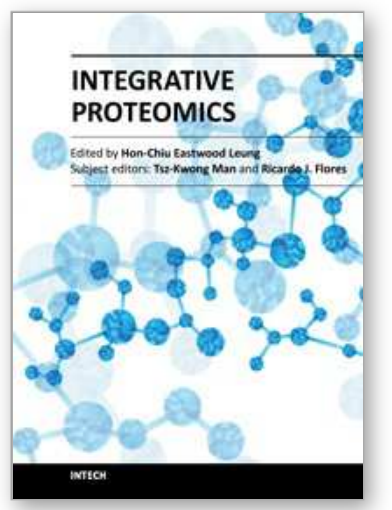

\author{
Integrative Proteomics \\ Edited by Dr. Hon-Chiu Leung
}

ISBN 978-953-51-0070-6

Hard cover, 442 pages

Publisher InTech

Published online 24, February, 2012

Published in print edition February, 2012

Proteomics was thought to be a natural extension after the field of genomics has deposited significant amount of data. However, simply taking a straight verbatim approach to catalog all proteins in all tissues of different organisms is not viable. Researchers may need to focus on the perspectives of proteomics that are essential to the functional outcome of the cells. In Integrative Proteomics, expert researchers contribute both historical perspectives, new developments in sample preparation, gel-based and non-gel-based protein separation and identification using mass spectrometry. Substantial chapters are describing studies of the sub-proteomes such as phosphoproteome or glycoproteomes which are directly related to functional outcomes of the cells.

Structural proteomics related to pharmaceutics development is also a perspective of the essence.

Bioinformatics tools that can mine proteomics data and lead to pathway analyses become an integral part of proteomics. Integrative proteomics covers both look-backs and look-outs of proteomics. It is an ideal reference for students, new researchers, and experienced scientists who want to get an overview or insights into new development of the proteomics field.

\title{
How to reference
}

In order to correctly reference this scholarly work, feel free to copy and paste the following:

Hiroshi Yamaguchi, Masaya Miyazaki and Hideaki Maeda (2012). Simple and Rapid Proteomic Analysis by Protease-Immobilized Microreactors, Integrative Proteomics, Dr. Hon-Chiu Leung (Ed.), ISBN: 978-953-510070-6, InTech, Available from: http://www.intechopen.com/books/integrative-proteomics/simple-and-rapidproteomic-analysis-by-protease-immobilized-microreactors

\section{INTECH}

open science | open minds

\section{InTech Europe}

University Campus STeP Ri

Slavka Krautzeka 83/A

51000 Rijeka, Croatia

Phone: +385 (51) 770447

Fax: +385 (51) 686166

www.intechopen.com

\section{InTech China}

Unit 405, Office Block, Hotel Equatorial Shanghai

No.65, Yan An Road (West), Shanghai, 200040, China 中国上海市延安西路65号上海国际贵都大饭店办公楼 405 单元

Phone: $+86-21-62489820$

Fax: +86-21-62489821 
(C) 2012 The Author(s). Licensee IntechOpen. This is an open access article distributed under the terms of the Creative Commons Attribution 3.0 License, which permits unrestricted use, distribution, and reproduction in any medium, provided the original work is properly cited. 